\title{
ESTRATÉGIAS DE ENSINO-APRENDIZAGEM COM BASE EM TECNOLOGIAS DIGITAIS: UMA ANÁLISE COM PROFESSORES E COORDENADORES PEDAGÓGICOS DOS ANOS INICIAIS
}

\author{
Nicole Samanta dos Santos de Roma - nicolleroma@gmail.com - Universidade \\ Regional de Blumenau (FURB) \\ Maurício Capobianco Lopes - mclopes@ furb.br - Universidade Regional de Blumenau \\ (FURB)
}

Resumo: As tecnologias digitais são recursos importantes na sala de aula dos anos iniciais. Com base nisso, o objetivo da presente pesquisa foi analisar as estratégias de ensino-aprendizagem utilizadas pelos professores que estão inserindo as tecnologias digitais na sala de aula dos anos iniciais. A pesquisa teve caráter qualitativo descritivo e foi realizada em uma escola pública e duas escolas particulares. Os sujeitos da pesquisa foram quatro professoras que trabalham nos anos iniciais e duas coordenadoras pedagógicas. Os resultados da pesquisa evidenciaram como se deu a inserção das tecnologias digitais na escola e como os professores a utilizam $e$ revelaram que ainda há muito o que fazer mesmo nessas escolas que estão inserindo as tecnologias digitais no seu contexto.

Palavras-chave: Tecnologias digitais na educação. Estratégias de ensinoaprendizagem. Anos iniciais.

\section{TEACHING AND LEARNING STRATEGIES BASED ON DIGITAL TECHNOLOGIES: AN ANALYSIS WITH TEACHERS AND PEDAGOGICAL COORDINATORS OF THE BEGINNING GRADES}

\begin{abstract}
Digital technologies are important resources in the classroom of primary schools. Based on this, this article aims to analyze the teaching and learning strategies used by the teachers who are inserting the digital technologies in classrooms of the beginning grades. The research has qualitative and descriptive characteristics and was performed in a public school and two private schools. The subjects of the research were four teachers that work in the beginning grades and two pedagogical coordinators. The survey results showed how has occurred the insertion of digital technologies in these schools and how teachers use them, and revealed that there is still much to do even in schools that are inserting the digital technologies in their context.
\end{abstract}

Key-words: Digital technologies in education. Teaching and learning strategies. Beginning grades.

\section{INTRODUÇÃO}

A sociedade atual tem formas diferentes de pensar, de aprender e de se relacionar em relação às gerações passadas. Coll e Monereo (2010, p. 15) afirmam que "o fato significativo é que essa nova sociedade se sustenta, em grande medida, no desenvolvimento espetacular das TIC". Por conta disto, a escola não pode ser algo fora dessa sociedade. Sendo assim, Sibilia (2012, p. 65, grifos da autora), ressalta que "a sala de aula escolar tenha se convertido em algo terrivelmente "chato"".

Vivemos hoje numa sociedade tecnológica, da qual a escola não deve ficar de fora. Existem muitas discussões sobre a inserção das tecnologias digitais nas escolas, mas ainda há pouca mudança efetiva com impacto nos processos de ensinoaprendizagem. A identificação de iniciativas inovadoras com base em tecnologias 
digitais pode contribuir para a melhoria do processo de ensino-aprendizagem nos anos iniciais.

Segundo Moran (2013, p.13):

Uma educação inovadora se apoia em um conjunto de propostas com alguns grandes eixos que lhe servem de guia e de base: o conhecimento integrador e inovador; o desenvolvimento da autoestima e do autoconhecimento (valorização de todos); a formação de alunos empreendedores (criativos, com iniciativa) e a construção de alunos cidadãos (com valores individuais e sociais).

Ressalta-se que não são somente as tecnologias digitais que tem o potencial de mudar os paradigmas tradicionais da escola por isso é preciso que professores e alunos trabalhem em conjunto para uma escola inovadora, como afirma Moran (2004).

Uma questão importante é entender como as escolas irão fazer a inserção das tecnologias digitais no contexto escolar dos estudantes. É um processo difícil, pois é preciso compreender como as crianças querem e precisam aprender e de que forma $o$ professor pode ajudar neste processo. O professor pode facilitar o processo de ensinoaprendizagem, fazendo com que o mesmo seja significativo tanto para as crianças quanto para eles mesmos. Segundo Bacich, Tanzi Neto e Trevisani (2015, p. 47), "Estruturalmente, a escola atual não difere daquela do início do século passado. No entanto, os estudantes de hoje não aprendem da mesma forma que os do século anterior". Por isso, as tecnologias digitais vêm para ajudar no processo de ensinoaprendizagem, trazendo possibilidades para a sala de aula.

Com base nessas inquietações decidiu-se estudar o tema problematizado e justificado em duas dimensões: profissional e acadêmica. No nível profissional percebese que existem muitas discussões sobre a inserção das tecnologias digitais nas escolas, mas ainda há pouca mudança efetiva com impacto nos processos de ensinoaprendizagem. As escolas continuam na transmissão em massa, na memorização e não efetivamente na construção de conhecimento e aprendizagem significativa. No nível acadêmico, percebe-se pouca ou nenhuma discussão sobre o tema nos cursos superiores de formação de professores.

Assim, este artigo analisa como os professores e coordenadores veem e aplicam estratégias de ensino-aprendizagem com base em tecnologias digitais nos anos iniciais. Como objetivos específicos destacam-se: identificar escolas com estratégias inovadoras nos anos iniciais quanto ao uso de tecnologias digitais; descrever a inserção das tecnologias digitais no contexto didático-pedagógico das escolas e analisar como os professores utilizam as tecnologias digitais na sala de aula.

\section{MÉTODO DA PESQUISA}

Essa pesquisa delineia-se em uma abordagem qualitativa e descritiva. Trata-se de uma pesquisa de campo em escolas inovadoras quanto à inserção desses recursos na sala de aula dos anos iniciais. Participaram da pesquisa duas escolas particulares e uma escola pública. A escola pública, localizada em Florianópolis (SC), foi criada em 1961 e atende desde o fundamental até o ensino médio. Uma das escolas particulares fica em Blumenau (SC). Foi fundada em 1953 e atualmente possui em torno de mil e duzentos alunos, divididos entre educação infantil, ensino fundamental e ensino médio. A outra escola particular está localizada em São Paulo (SP). Foi fundada em 1962 e trabalha desde a educação infantil até o ensino médio.

Foram entrevistados três professores dos anos iniciais, uma professora da educação infantil e duas coordenadoras pedagógicas. Em uma das escolas não foi possível entrevistar a coordenadora, pois a mesma estava em licença saúde. A entrevista teve como instrumento metodológico a gravação dos relatos, para então, coletar os 
dados. Pensando na ética do trabalho, a identidade das professoras e das escolas foram preservadas. Portanto, serão mencionados como p1, p2, p3, p4, c1 e c2, e as escolas como e1, e2 e e3. A p1 é professora da educação infantil, a p2 leciona para o segundo ano, a p3 trabalha com o terceiro ano e a p4 ministra aula para o primeiro ano, todas do ensino fundamental. As três escolas foram escolhidas por acessibilidade. A escolha dos professores entrevistados foi indicação das escolas.

Para a análise dos dados foram definidas categorias de acordo com os objetivos. As categorias usadas na análise são apresentadas na Tabela 1.

Tabela 1 - Categorias de análise

\begin{tabular}{|c|c|}
\hline Objetivos & Categorias \\
\hline \multirow{5}{*}{$\begin{array}{l}\text { descrever a inserção } \\
\text { das tecnologias digitais } \\
\text { no contexto didático- } \\
\text { pedagógico das escolas }\end{array}$} & Ideia: entender como surgiu a ideia de inserir as tecnologias digitais na escola. \\
\hline & $\begin{array}{l}\text { Gestão: compreender como a gestão da escola ajudou os professores durante o } \\
\text { processo de inserção das novas tecnologias. }\end{array}$ \\
\hline & $\begin{array}{l}\text { Reação (crianças e professores): entender porque as reações das crianças são } \\
\text { diferentes das reações dos professores. }\end{array}$ \\
\hline & $\begin{array}{l}\text { Formação: analisar como as escolas e professores buscam as formações para } \\
\text { trabalharem com esses equipamentos em sala de aula. }\end{array}$ \\
\hline & Tempos e espaços: compreender como os professores planejam esses aspectos. \\
\hline \multirow{3}{*}{$\begin{array}{l}\text { analisar como os } \\
\text { professores utilizam as } \\
\text { tecnologias digitais na } \\
\text { sala de aula. }\end{array}$} & $\begin{array}{l}\text { Estratégias: analisar como os professores organizam as estratégias para o uso } \\
\text { das tecnologias. }\end{array}$ \\
\hline & $\begin{array}{l}\text { Avaliação: analisar como os professores avaliam as crianças durante a } \\
\text { utilização das tecnologias digitais. }\end{array}$ \\
\hline & $\begin{array}{l}\text { Ferramentas: compreender como essas ferramentas são planejadas para a } \\
\text { utilização na sala de aula. }\end{array}$ \\
\hline
\end{tabular}

\section{ANÁLISE}

Neste capítulo apresentamos os dados analisados e coletados, por meios de entrevistas aplicada com quatro professoras (p) e duas coordenadoras (c), que trabalham com os anos inicias, em duas escolas particulares e uma escola pública.

\subsection{DESCRIÇÃO DAS ESCOLAS}

A e1 é uma escola particular de São Paulo (SP). Ela foi escolhida pois possui uma sala Google, localizada no meio da escola. Suas paredes são de vidro o que permite que do lado de fora se tenha a visão do que acontece do lado de dentro. A sala tem tablets, duas televisões para espelhar os tablets, caixa de som, entre outras tecnologias.

A e2 é uma escola pública de Florianópolis (SC). Ela foi escolhida pois alguns professores utilizam os tablets na sala de aula. A escola também tem um Laboratório Interdisciplinar de Formação de Educadores (LIFE). Os professores levam as crianças ao laboratório para utilizarem as tecnologias disponíveis.

A e3 é uma escola particular de Blumenau (SC). Ela foi escolhida pois tem um núcleo de tecnologias que programa as atividades em jogos para as crianças utilizarem na sala de aula. Essa escola retirou o laboratório de informática e utiliza somente tablets.

\subsection{INSERÇÃO DAS TECNOLOGIAS NO CONTEXTO DIDÁTICO- PEDAGÓGICO DA ESCOLA}

Nessa seção são analisadas as categorias relacionadas ao primeiro objetivo específico do trabalho apresentado no Tabela 1. A primeira categoria trata sobre a ideia da inserção das tecnologias digitais na escola e de quem veio essa iniciativa. A p2 esclarece que essa inserção foi aos poucos e com iniciativa da gestão da escola.

"Bom, ela começou primeiro com a aula de informática, que nós vínhamos com as crianças na aula de informática, e aí era o professor e a gente só fazia o papel de mediador. Aí depois 
quando inaugurou a sala google (...), aí a gente começou a ser capacitados para trabalhar com esse espaço mesmo, que é um espaço completamente diferenciado e totalmente ligado na rede. Tudo lá é online, aí a gente começou a ter algumas capacitações, entraram os tablets e os google chromes, que são os computadores que funcionam totalmente online mesmo."

Neste relato percebe-se que a escola inseriu as novas tecnologias no seu contexto aos poucos. A escola se preocupou em capacitar seus professores para trabalharem com as crianças utilizando esses novos instrumentos. Quando perguntada sobre quem teve a iniciativa de inserir as tecnologias digitais na escola, ela responde

"Veio da gestão, a gestão que iniciou o processo e a gente foi correndo atrás né"

A c2 destaca que a escola inseriu as tecnologias digitais devagar e para isso fizeram alguns cursos para entenderem essa inserção.

"Tudo aconteceu e foi imposto ao professores e alunos, foi indo devagarinho, a escola ela sempre teve esse lado tecnológico aguçado. Então a gente sempre participou de muitos cursos. A gente começou com palestras de sensibilização com a equipe, e a hora que a gente viu já tinha essa parceria com a Google, a gente abriu essa google learner space, essa sala com parceria com a google, primeira sala mundial e aí parece que a escola toda ficou mais motivada e também lógico, conforme a gente foi vendo os resultados, lógico que isso serve como um incentivo, conforme você vai vendo que está dando certo, que funciona, que o ensino fica mais dinâmico, que as crianças ficam mais interessadas."

A p3 destaca que a inserção das tecnologias digitais partiu dos professores, pois segundo ela a gestão da escola é composta pelos próprios professores.

"Não saberia te dizer como começou, (...). Então de início eu penso que os professores sim, se mobilizaram para conseguir né?"

A p4 destaca que a ideia da inserção das tecnologias digitais na escola veio por parte da gestão escolar.

"Na nossa escola, primeiro a gente tinha um laboratório de informática, só que dai o que eles perceberam, que aquele laboratório de informática fica restrito a uma turma só. (...) Então eles optaram por desmanchar todo o laboratório e colocaram aulas móveis, que daí tem os equipamentos com os tablets. (...) A gente pode tá usando o tablet e não precisa de alguém junto na sala pra tá fazendo essa aula."

No relato da p4 percebe-se que essa escola tem uma preocupação com as tecnologias digitais. Não inseriram de qualquer forma, tiveram todo um planejamento. Assim, podem utilizar os tablets diversas turmas ao mesmo tempo e em espaços diferentes. Quando foi perguntada sobre de quem foi a iniciativa de inserir as novas tecnologias na escola, ela respondeu:

"Foi da escola, porque daí tem o núcleo de tecnologias. Então o pessoal do núcleo junto com o diretor, com a gestão que viu que não estava mais sendo viável assim o laboratório."

A c1 destaca que os professores começaram a ser mais dinâmicos nas aulas.

"Nós começamos aos poucos né?, primeiro com laboratório fixo de informática e aos poucos (...) trazendo o tablet para a sala de aula, porque daí o uso individual sem que as crianças precisassem ir para a sala fixa (...)e os professores puderam ser mais dinâmicos nas aulas."

Quando perguntada sobre de quem veio a ideia de colocar tablets na escola, ela respondeu que foi a gestão da escola.

"ela veio por parte da equipe pedagógica da escola né? Da escola, da direção e da equipe pedagógica que pensou e viu para onde a gente teria que ir, claro que o núcleo de tecnologias que dá todo o suporte técnico pra escola (...)."

Percebe-se pela fala dos entrevistados que há um trabalho em conjunto para inserir as tecnologias digitais no contexto escolar. Como Moran (2004) afirma, não são só as tecnologias digitais sozinhas que irão transformar a escola. É preciso um trabalho em conjunto entre professores, gestores, pais e estudantes. Segundo Moran (2004, p. 63), "Ensinar com as novas mídias será uma revolução se mudarmos simultaneamente os paradigmas convencionais do ensino, que mantêm distantes professores e alunos. Caso contrário, conseguiremos dar um verniz de modernidade, sem mexer no essencial". Além de inserir as tecnologias digitais na escola, é importante também mudar a forma de lecionar e a estrutura da escola. 
A categoria seguinte questionou como se deu o apoio da gestão para o uso de tecnologias. Neste sentido, a p2 declarou que:

"Ela inseriu tudo e ela pediu que a gente fizesse um trabalho em cima. Então da coordenação teve ideias, alguns incentivos pra gente trabalhar, conseguiu para os professores comprarem os tablets, conseguiu material".

A p4 também falou sobre como a gestão a apoiou.

"Eles fizeram umas formações com a gente. Então, assim, foi explicado como é que seria, o pessoal da tecnologia falou como é que usava, deu todo o suporte". diferente:

Nesses dois casos fica visível que a gestão apoiou os professores. A fala da p3 é

"É que a gestão da escola, é composta na verdade são os próprios professores. Então a própria diretora foi eleita, é professora na escola né? Os coordenadores então, na verdade é um conjunto que se faz, é um ciclo."

A fala de c1 é parecida com as respostas das p2 e p4.

"De que maneira... Oferecendo formação, estando a disposição sempre que algum momento, alguma sala de aula surge dúvidas, nós tínhamos uma equipe preparada para poder ir. Então eles poderiam vir antes, quando preparavam aula, procurar o suporte da coordenação."

Destaca-se que c2 tem uma visão similar a c1. Para a inserção das tecnologias digitais na escola é essencial o apoio da gestão para oferecer maior segurança aos professores quando houver alguma dúvida sobre a sua utilização na sala de aula. Nessa visão, professores e gestão precisam trabalhar juntos para uma inserção de qualidade para o uso dessa nova maneira de se ensinar e aprender.

Outra categoria aborda a reação das crianças e professores com a inserção das tecnologias no contexto escolar. A partir das opiniões dos entrevistados sobre essa categoria percebeu-se que a maioria das reações são parecidas. Para as crianças acontece naturalmente, pois as tecnologias digitais fazem parte do seu cotidiano, mas para alguns professores ainda é um desafio. Assim, muitos não sabem lidar com esse novo jeito de ensinar e aprender. A p4 afirma que:

"As crianças amaram, é os professores que foram o problema, porque tablet era muito novo. Então a gente não sabia como usar, pra gente assim ó, alguém da informática quando estava junto era uma segurança".

A p3 comentou sobre crianças que ainda não têm acesso a tecnologias em casa:

"As crianças ficaram bem felizes, bem empolgados até porque muitos já usam em casa, mas uma boa parte ainda não tem esse acesso em casa. Então na escola seria uma maneira deles estarem utilizando né? Esses materiais, então pra eles foi muito bom."

Esses resultados apontam para a importância da inserção das tecnologias digitais no contexto escolar, pois as crianças sentem-se mais motivadas e a sala de aula deixa de ser algo desinteressante, como Sibilia (2012) afirma ter se tornado nos dias de hoje.

As visões dos coordenadores sobre a reação dos professores são parecidas, pois ambas relatam que no começo os professores tinham receio, mas aos poucos isso foi mudando, como afirma a c1:

"professores também gostaram, mas no início ficaram com um pouco de resistência (...) Porque nós não somos nativos digitais né?, Então os professores tem um pouquinho mais de dificuldade, mas como a escola se pôs a disposição de dar todo o suporte necessário e formação aos poucos eles foram gostando e depois foi tranquilo, mas no começo assustou um pouco."

A reação positiva das crianças ocorre pelo motivo de que, via de regra, o ensino está focado na escola e não nos seus estudantes (CHRISTENSEN; HORN; JOHNSON, 2012). Assim, os estudantes acreditam que as tecnologias digitais mudam as escolas, para que elas sejam mais lúdicas e mais dinâmicas, ao contrário do que é hoje.

A categoria seguinte aborda sobre como os entrevistados pensam como é o processo de formação para o uso das tecnologias digitais. A p1 diz que:

"Eu busco, eu acho que na minha opinião a tecnologia tá cada vez mais fácil de ser acessada, (...) Eu sou uma pessoa curiosa, talvez eu nunca fiz um curso fora da escola de capacitação em relação a isso, eu mexo o tempo inteiro, eu fuço, eи sou curiosa, eu baixo aplicativo, eu tento 
usar. Quando eu não consigo fazer eu venho aqui que tenho apoio e digo que não estou conseguindo e eles me ajudam".

A p4 tem visão semelhante:

"agora não tá tendo, mas no início, quando surgiu os tablets, e que vieram e que desmancharam o laboratório de informática, aí foi feito uma série de formações assim, da importância, de como utilizar, porque era muito desconhecido ainda".

Quando foi perguntado para a p4 se ela busca formações além que a sua escola oferece ela relata que: "Eu não procuro outras." A p2 diz que:

"Tem uma capacitação que é feita uma vez por mês e se você quiser você pode vir, fica a critério de cada professor se vem ou não. E foi isso que a gente teve e o resto é muito de você usar entendeu? Foi uma coisa que partiu muito mais dos professores e ele deram algumas capacitações, mas como é muito ampla, (...). Eu acho que essa parte da informática ela é muito intuitiva, acho que não existe tanto curso assim, é muito mais de você usar e perder um tempo, trabalhando em cima e entender como funciona, do que toda uma capacitação, eu pessoalmente aprendi tudo sozinha, eu acho mais fácil, você ir mexendo, procurando e ir errando e acertando do que você ter uma capacitação, por que não é uma coisa assim muito técnica, (...)’”.

A p3 diz que a formação não acontece nem por iniciativa dela nem da escola.

"Assim, durante todo o período que eu estive ali tanto em 2008 e 2009, quanto agora, assim, não teve nenhum tipo de formação né? É professor usa porque gosta, porque já sabe utilizar, porque não existe um apoio (...) Não existe um setor que cuide disso né? Ou uma formação sobre isso, também não existe (...)".

Pelo relato dos entrevistados percebe-se que ainda há muito a fazer nesse aspecto pois, segundo Vaillant e Marcelo (2012, p. 81), a formação deve "atender de maneira especial à pessoa que aprende, considerando a situação ou o espaço onde atua, interage e aprende o aluno e a utilização de ferramentas e meios que facilitam o aprendizado". Percebe-se que há pouca informação sobre as capacitações e que as professoras entrevistadas não procuram uma formação que atenda às suas necessidades profissionais. A formação é importante para a compreensão de como trabalhar com essas novas tecnologias na escola, para que elas facilitem o aprendizado dos estudantes. Assim, é preciso que professores e escolas invistam em formações para aprimorar os seus conhecimentos e aprendam como as novas tecnologias podem contribuir na aprendizagem de suas crianças.

A última categoria nesse grupo trata da organização dos tempos e dos espaços para a utilização das tecnologias digitais. Todos os professores relataram que precisam agendar os espaços e os equipamentos para utilizar com a sua turma. A p2 relata como organiza os tempos e os espaços:

"Então a sala (...)você tem que agendar com uma certa antecedência para você conseguir usar, os tablets é igual você tem que agendar para conseguir, e nós temos a sala de multimídia que você também pode usar as tecnologias, todos os espaços tem que agendar. Na sala de aula do fundamental não dá pra usar, porque ainda não tem infraestrutura, não tem data show, (...)”.

Ela não detalhou como utiliza esses espaços e como os organiza para as crianças utilizarem as tecnologias digitais. Já a p3 não falou como organiza seu tempo e espaço, mas destacou como insere as tecnologias digitais na sala de aula.

"Eu acho que assim, na verdade não é uma coisa que você planeja pra tecnologia entende? Eu vejo por exemplo, muito o que eu vou trabalhar e esse assunto, eu vejo o que eu posso está trazendo de formas diferentes pra esse aluno né? (...) Então assim, eu tento possibilitar o maior número de atividades possíveis pra esse aluno. Não tento como objetivo a tecnologia, entende?"

Ela procura priorizar a aprendizagem dos estudantes da maneira mais produtiva e significativa independente do meio tecnológico. A forma de trabalho dela é semelhante ao proposto por Bacich, Tanzi Neto e Trevisani $(2015,51)$ :

Um projeto de personalização que realmente atenda aos estudantes requer que eles, junto com o professor, possam delinear seu processo de aprendizagem, selecionando recursos que mais se aproximam de sua melhor maneira de aprender. Aspectos como o ritmo, o tempo o lugar e o modo como aprendem são relevantes [...]. 
A p4 diz que o tempo é estipulado pela escola, mas se precisar pode usar mais:

"Então, o espaço é a sala de aula... (...) Então eu vou lá e digito que vou usar naquela data e naquele horário eu vou lá e busco a bolsinha com os tablets e levo pra minha sala e lá a gente faz a aula. Assim, é uma vez por semana que eu posso usar, tipo assim, respeitando a todos né? Claro que se eu tiver uma atividade que usar um pouco a mais, eu posso também né? Só que, o que a escola pede é que essa semana eu use o tablet em algum momento".

A professora relatou como ela organiza a sala de aula. As crianças sentam em duplas e, assim, trabalham cooperativamente uma com a outra. Bacich, Tanzi Neto e Trevisani $(2015,62)$ afirmam que "É importante que o processo de ensino e aprendizagem ocorra de forma colaborativa, com foco no compartilhamento de experiências e na construção do conhecimento por meio das interações com o grupo". A forma como as professoras utilizam o tempo e organizam o espaço está de acordo com o que defendem Coll, Mauri e Onrubia (2010), que consideram que os professores podem organizar espaços de aprendizagem individual ou coletivo e disponibilizar ferramentas e aplicativos para o trabalho colaborativo. É fundamental ter um tempo e um espaço planejado para utilizar as tecnologias digitais. Por isso, as escolas agendam os equipamentos e os espaços para os professores.

As observações dessa seção permitem perceber que o envolvimento da gestão é fundamental no processo e que a formação de professores ainda precisa melhorar. $\mathrm{O}$ planejamento é uma preocupação constante e na organização dos tempos e espaços há estratégias diferentes entre as escolas. Por fim, observa-se que as crianças reagem de forma natural à inserção das tecnologias, mas para os professores esse ainda é um desafio.

\subsection{VISÃO DOS PROFESSORES SOBRE O USO DAS TECNOLOGIAS}

A primeira categoria que trata da visão dos professores sobre o uso das tecnologias digitais aborda suas estratégias. A p1 diz.

"Dependendo do planejamento e do objetivo eu faço a atividade individual, cada um no seu tablet ou espelho o jogo na TV e vem um de cada vez jogar e todos veem o que tá acontecendo." A p2 destaca:

"por exemplo, quando eu vou dar ciências eu sei de um aplicativo que tem as partes das plantas, aí eu trabalho com esse aplicativo e junto com o livro de ciências didático. E a gente vai trabalhando assim, ela só entra para complementar, ela não entra para substituir nada".

A p3 relata:

"Ai dentro desse tema ou desse projeto eu tento elencar junto com os alunos, quais fontes a gente pode tá pesquisando e de quais formas a gente pode tá chegando a esse conhecimento. E geralmente eles tão falando youtube, rede social, as vezes tem um blog que fala do assunto, um livro, então a gente vai mapeando. A estratégia na verdade não é pro uso da tecnologia em si, não como foco, mas como um meio de pesquisa, assim como existe o livro, existe a internet, existem os blogs."

A p3 destaca a participação das crianças que escolhem de que maneira querem aprender, dando sugestões para a professora. Segundo Santos (2015, p. 116), "quando é o aluno quem está dirigindo seu aprendizado, cabe ao professor o papel de orientador e avaliador constante". Para Schneider (2015), o estudante deve deixar de ser espectador e precisa vir a ser o protagonista da sua aprendizagem. Silva e Claro destacam que (2007, p. 83), "o papel do professor não é transmitir conhecimento, mas criar as possibilidades para sua própria produção ou construção". Logo o papel do professor se transforma. Ele deixa de ser transmissor e passa a ser mediador.

Outra categoria trata da avaliação feita pelos professores quando as crianças estão utilizando as tecnologias digitais. A p2 explica que é uma avaliação formativa, que o professor vai observando o que as crianças estão conseguindo fazer.

"A avaliação aí ela é mais formativa do que avaliativa mesmo, é uma avaliação que você vai, é um processo que você acompanha desde a primeira parte quando eles começam, você 
estabelece objetivos e esse objetivos tem que ser alcançados. (...) Então são coisas que a gente vai trabalhando, que não é uma avaliação normal, uma prova, não é nada disso, é acompanhar o processo todo deles."

A p3 diz que a avaliação também é por observação.

"a avaliação é uma observação do que o aluno tá fazendo, se ele tá conseguindo, se ele está conseguindo chegar no objetivo proposto. E aí nesse momento é a questão da observação mesmo, não tem muita, vamos dizer assim, é dado quantitativo né? (...) Então a gente tem os critérios, é uma descrição do que o aluno conseguiu né?"

A p4 destaca a preocupação de acompanhar todos.

“...o meu é aquele negócio de tá olhando mesmo. Então assim, eu vou de um em um, pra ver se tá fazendo, quantos erros fez, quantos acertos, aí eu vejo se tá com dificuldade, aí eles chamam na mesa. Então é mais complicado, porque se eu não ficar o tempo inteiro em cima, eu não consigo como mensurar isso."

Segundo Masetto (2004), a avaliação precisa trazer informações necessárias para que as crianças possam refletir sobre o seu processo de aprendizagem. Percebeu-se que as professoras entrevistadas não relataram sobre retornar a avaliação para as crianças. Segundo Rodrigues (2015, p.128), "A avaliação deve verificar o processo de aprendizagem do aluno e, por este ser o seu foco, retornar a ele pelo resultado".

A última categoria desta seção trata das ferramentas que os professores utilizam em suas atividades. A p4 relatou que o núcleo de tecnologias da sua escola produz os jogos para os professores utilizarem com as crianças.

“...a gente tem um conteúdo pra passar, (...) então eu mando um email pro laboratório de tecnologia, peço pra eles desenvolverem uma atividade que vá trabalhar, aí eu dou sugestões, um jogo da memória, ou jogo de ganhar pontos, aí eu especifico um pouquinho do que eu pretendo né? Aí eles desenvolvem a atividade, daí eles mandam pro professor que pediu”.

A p3 explica que utiliza as ferramentas propostas pelos estudantes, a partir do tema da aula.

"Eu levo muito pelo o que os alunos vão propondo né? As turmas de quinto anos são maiores e já tem um conhecimento maior, já as turma de terceiros já são menores, alguns tem o acesso limitado pelos pais, então eles gostam muito de blogs, eles gostam muito de jogos(...) para a construção do conhecimento."

A p2 fala sobre as ferramentas que utiliza na sala com as suas crianças.

"Olha, a gente utiliza tabletes, chromes books, apple TV, a gente utiliza... (...), aí a internet como um todo, a gente usa aplicativos como google maps, e vários outros aplicativos (...)."

Bacich, Tanzi Neto e Trevisani (2015, p. 49) afirmam que "as tecnologias digitais oferecem diferentes possibilidades de aprendizagem e, se bem utilizadas pelas escolas, constituem-se como oportunidade para que os alunos possam aprender mais e melhor". A fala dos entrevistados vai de acordo com os autores. Quando professores escolhem bem as ferramentas, o potencial de aprendizagem das crianças é maior.

As observações dessa seção permitem perceber que ainda é necessário evoluir na questão metodológica e que apenas uma professora planeja em conjunto com as crianças. As ferramentas são diversificadas e em um caso vai de acordo com o que as crianças propõem. Por outro lado, a avaliação precisa ser revista, pois as crianças precisam compreender o processo de aprendizagem, para então refletir sobre ele, o que não está evidenciado na fala das entrevistadas.

\section{CONCLUSÕES E RECOMENDAÇÕES}

Esta pesquisa teve como objetivo analisar como os professores e coordenadores veem e aplicam estratégias de ensino e aprendizagem com base em tecnologias digitais nos anos iniciais. Para que esse objetivo fosse alcançado, foram organizadas entrevistas com professores que utilizam as tecnologias digitais no contexto escolar e com os coordenadores pedagógicos das escolas. Inicialmente buscou-se identificar escolas inovadoras quanto ao uso das tecnologias digitais. Identificamos três escolas com iniciativas inovadoras com base em tecnologias digitais. Em duas dessas escolas o 
grupo todo de professores trabalha com as tecnologias na sala de aula. Na outra escola, não são todos os professores que inseriram as novas ferramentas tecnológicas no contexto escolar. Sendo assim, analisamos as estratégias inovadoras que os professores realizam com as suas crianças junto com as tecnologias digitais. $\mathrm{O}$ que se percebeu é que as escolas selecionadas utilizam as tecnologias digitais para além do laboratório de informática, priorizando dispositivos móveis, que podem ser utilizados em diferentes espaços da escola.

Também buscou-se compreender a inserção das tecnologias digitais na sala de aula. Nas análises encontramos muitas respostas positivas sobre essa questão. Nas escolas em que a gestão teve a iniciativa de fazer a inserção, as mudanças estão mais adiantadas. A fala dos entrevistados evidencia que é preciso investir mais em formação de professores, tanto no contexto do projeto pedagógico da escola, quanto na própria iniciativa dos professores em buscar essas formações. Por outro lado, as entrevistadas relatam que planejam os tempos e os espaços e os objetivos do uso das tecnologias digitais. Ao nosso ver esse planejamento é fundamental para uma melhor organização didático-pedagógica no uso desses recursos. Com base nisso, conclui-se que existem pontos fortes e fracos que precisam ser ainda trabalhados na inserção das tecnologias digitais na escola.

Por fim, analisou-se como os professores utilizam as tecnologias digitais na sala de aula. Observou-se que apenas uma das entrevistadas trabalha de modo dialógico com os estudantes no uso das tecnologias digitais. As demais mantêm a lógica tradicional onde o professor é o transmissor do conhecimento, mesmo usando as tecnologias. Portanto, fica claro que ainda há muito o que fazer em relação às estratégias dos professores que utilizam esses recursos. Em relação às avaliações observou-se que a mesma não retorna aos estudantes de modo a fazê-los refletir sobre a sua aprendizagem. A avaliação deveria retornar às crianças para que elas compreendessem o seu processo de aprendizagem, independente do uso das tecnologias digitais. Por outro lado, as tecnologias têm o potencial de ampliar as possibilidades de feedback no processo avaliativo. Quanto às ferramentas, observou-se uma diversidade de ferramentas nas escolas que contribuem, cada uma a seu modo, para a construção do conhecimento das crianças. Isso evidencia as possibilidades diversas de aplicação das tecnologias digitais em sala de aula, sobretudo considerando que todas têm suas ferramentas baseadas em tablets. A análise dessa questão permite inferir que as escolas ainda precisam investir na questão metodológica e avaliativa no uso das tecnologias digitais.

Dessa forma, ao concluir esta pesquisa, ressaltamos a importância das tecnologias digitais na escola. Esses novos recursos contribuem para uma melhor aprendizagem das crianças e professores. As novas tecnologias são possibilidades para os professores planejarem as suas aulas de uma maneira diferente, permitindo aos estudantes uma maneira deles serem autônomos nos processos de aprendizagem. Os resultados apontam, por meio das respostas dos entrevistados, que as escolas já têm resultados e inovações, mas que ainda há um longo caminho a percorrer em relação a inserção das tecnologias digitais na escola. Além da inserção desses recursos, é necessário mudar a estrutura completa das escolas, desde as concepções metodológicas até a estrutura física.

\section{REFERÊNCIAS}

BACICH, Lilian; TANZI NETO, Adolfo; TREVISANI, Fernando de Mello (Org.): Ensino híbrido: personalização e tecnologia na educação. Porto Alegre: Penso, 2015. 
CHRISTENSEN, Clayton M.; HORN, Michael B.; JOHNSON, Curtis W. Inovação na sala de aula: como a inovação disruptiva muda a forma de aprender. Tradução: Rodrigo Sardenberg. - Porto Alegre: Bookman, 2012.

COLL, César, MAURI, Teresa e ONRUBIA, Javier. A incorporação das tecnologias da informação e da comunicação na educação. IN: COLL, César; MONEREO, Carles. Psicologia da educação virtual: aprender e ensinar com as tecnologias da informação e da comunicação. Porto Alegre: Artmed, 2010.

COLL, César; MONEREO, Carles. Educação e aprendizagem no século XXI, novas ferramentas, novos cenários, novas finalidades. IN: COLL, César e MONEREO, Carles. Psicologia da educação virtual: aprender e ensinar com as tecnologias da informação e da comunicação. Porto Alegre: Artmed, 2010.

MASETTO, Marcos T: Mediação pedagógica e o uso da tecnologia. IN: MORAN, José Manuel, MASETTO, Marcos T., BEHRENS, Marilda Aparecida. Novas tecnologias e mediação pedagógica. Campinas, SP: Papirus, 2004.

MORAN, José Manuel: Ensino e aprendizagem inovadores com tecnologias audiovisuais e telemáticas. IN: MORAN, José Manuel, MASETTO, Marcos T., BEHRENS, Marilda Aparecida. Novas tecnologias e mediação pedagógica. Campinas, SP: Papirus, 2004.

MORAN, José Manuel: Ensino e aprendizagem inovadores com tecnologias audiovisuais e telemáticas. IN: MORAN, José Manuel, MASETTO, Marcos T., BEHRENS, Marilda Aparecida. Novas tecnologias e mediação pedagógica. Campinas, SP: Papirus, 2013.

RODRIGUES, Eric Freitas. A avaliação e a tecnologia: a questão da verificação de aprendizagem no modelo de ensino híbrido. IN: BACICH, Lilian, TANZI NETO, Adolfo e TREVISANI, Fernando de Mello(Org.): Ensino híbrido: personalização e tecnologia na educação. Porto Alegre: Penso, 2015.

SANTOS, Glauco de Souza. Espaços de aprendizagem. IN: BACICH, Lilian, TANZI NETO, Adolfo e TREVISANI, Fernando de Mello(Org.): Ensino híbrido: personalização e tecnologia na educação. Porto Alegre: Penso, 2015.

SCHNEIDER, Fernanda: Otimização do espaço escolar por meio do modelo de ensino híbrido. IN: BACICH, Lilian, TANZI NETO, Adolfo e TREVISANI, Fernando de Mello (Org.): Ensino híbrido: personalização e tecnologia na educação. Porto Alegre: Penso, 2015.

SIBILIA, Paula. Redes ou paredes: a escola em tempos de dispersão. Rio de Janeiro: Contraponto, 2012.

SILVA, Marco; CLARO, Tatiana. A docência online e a pedagogia da transmissão. Boletim Técnico do Senac, v. 33, n. 2, p. 81-89, 2007.

VAILLANT, Denise; MARCELO, Carlos. Ensinando a ensinar: as quatro etapas de uma aprendizagem. 1 ed. Curitiba: Ed. UTFPR, 2012. 